\title{
Obtenção de materiais de alta tecnologia a partir de sementes de oleaginosas.
}

M. G. Fonseca $(P Q)^{*}$, L. N. Batista ${ }^{1}(P G)$, V. F. Silva ${ }^{1}(P G)$, V. S. Cunha ${ }^{1}(P Q)$, G. A. Romeiro $^{2}(\mathrm{PQ})$, C. N. Kunigami ${ }^{3}$ (PQ), M. C. C. Velloso ${ }^{2}(\mathrm{PG})$, M. R. Jesus ${ }^{1}(\mathrm{PG})$, T. C.

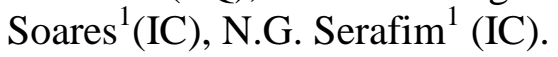

1-INMETRO - Instituto de Metrologia, Tecnologia e Qualidade Industrial - Av. Nossa Senhora das Graças, 50 - Xerém - Duque de Caxias - LAMOC.

2-UFF - Universidade Federal Fluminense - Outeiro de São João Batista s/n. - Valonguinho Niterói - Departamento de Química Orgânica.

3-INT - Instituto Nacional de Tecnologia - Av. Venezuela, 82 - Rio de Janeiro.

E-mail para contato: mgfonseca@inmetro.gov.br

RESUMO - A partir de sementes de oleaginosas podem ser produzidos diversos materiais, dentre esses se destaca a produção de biodiesel. O processo de extração gera dois produtos, o óleo utilizado para a obtenção de biocombustível e a torta, parte sólida. Através do processo de pirólise, são obtidos quatro produtos a partir da torta de extração: bio-oleo, carvão, gás e uma solução aquosa. Os produtos obtidos no processo de pirólise a baixa temperatura apresentam diversas aplicações, tais como: Bio-oleo, utilizado em fornos de aquecimento e produção de insumos químicos; carvão de pirólise utilizado em fornos, bioremediação de solo, filtros, engenharia civil, produção de carvão ativado, catalisadores e nanocarbonos; gás, que pode ser revertido para o aquecimento no processo pirolítico e uma solução aquosa rica em compostos nitrogenados, útil na irrigação de plantações. A aplicação da técnica de pirolise, no caso da semente de pinhão manso, levou a um carvão com potencial capacidade de adsorvente e através do óleo de pirólise obtido a partir da semente de inajá verificou-se uma aplicação como antioxidante, com aplicação em biodiesel.

\section{INTRODUÇÃO}

A humanidade busca encontrar soluções para os problemas desenvolvidos ao longo das gerações. O denominado avanço da modernidade desencadeou a formação de uma sociedade desigual em muitos sentidos e o denominado avanço tecnológico contaminou, desequilibrou o mundo atual através da poluição.

Tecnologias têm sido desenvolvidas na tentativa de obtenção de soluções para melhorar a qualidade de vida no planeta. A obtenção de energia renovável tornou-se uma boa saída para a substituição de combustíveis fósseis. Biodiesel tem se destacado entre tantas outras 
metodologias. A obtenção deste, a partir de sementes de oleaginosas é uma alternativa viável que engloba tanto aspectos ambientais como sócio econômicos. A utilização de sementes e de seus resíduos como fonte de energia, de produção de novos materiais (Rangabhashiyam et al, 2013) altamente tecnológicos faz parte de um novo conceito global denominado biorefinarias.

Pirólise a baixa temperatura (Bayer, 1992) consiste em uma técnica onde resíduos são aquecimentos a $380^{\circ} \mathrm{C}$ sob atmosfera inerte e onde, são obtidos quatro diferentes produtos: Biooleo, carvão pirolítico, solução aquosa e gás. O uso de pirólise a baixa temperatura se tornou uma alternativa viável para a obtenção de produtos de grande interesse (Romeiro et al, 2009), gerados a partir de resíduos orgânicos e industriais, por exemplo. A Figura 1, a seguir exemplifica um sistema de pirólise a baixa temperatura.

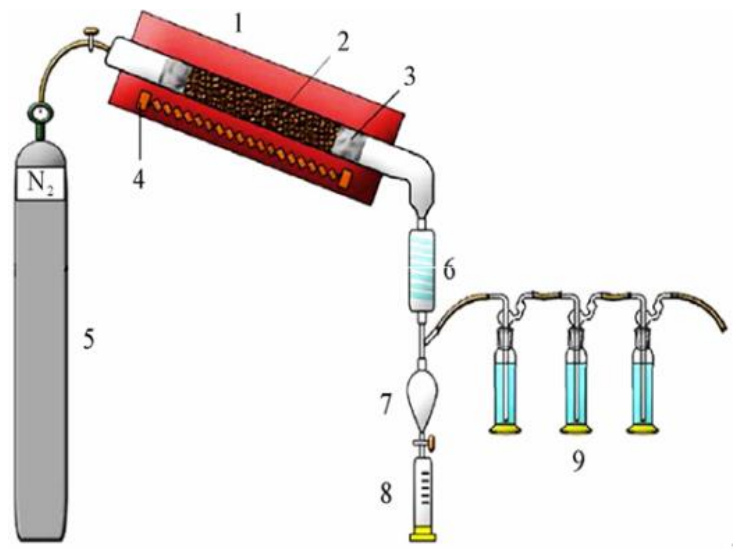

Figura 1: Equipamento de LTC: 1 - forno, 2 - amostra seca, 3 - lã de vidro, 4 - resistência elétrica, 5 - gás inerte, 6 - condensador, 7 - funil de separação, 8 - receptor para líquido e 9 - trap para gás.(PGQ/UFF).

O foco desse trabalho está diretamente relacionado à obtenção de produtos seguindo a política de química verde (Carrier, 2012), onde são gerados produtos através de uma tecnologia que não libere, produza produtos tóxicos e que não forneça uma grande quantidade de resíduos, evitando assim a contaminação do meio ambiente.

\section{RESULTADOS E DISCUSSÕES:}

Sementes de inajá (Attalea Maripa) foram secas, trituradas e extraídas por Soxhlet, utilizando hexano como solvente para a posterior obtenção de biodiesel. São gerados neste processo o produto líquido, óleo utilizado na obtenção de biodiesel e a parte sólida, torta de extração, utilizada na obtenção de produtos de maior valor energético.

A técnica de pirólise a Baixa Temperatura, consiste em um processo em um reator que utiliza uma curva de temperatura ascendente até $380^{\circ} \mathrm{C}$ e atmosfera inerte. O processo de pirólise é iniciado com o armazenamento da amostra no reator, seguida de uso de fluxo de nitrogênio durante todo o processo e posterior aquecimento de todo o sistema. Durante a etapa inicial de aquecimento, são obtidos os primeiros produtos líquidos, através da condensação dos mesmos em um condensador acoplado na saída do reator. São obtidos inicialmente água e óleo que são 
separados por processo de decantação. Ao continuar o aquecimento, segunda etapa do processo, ocorre à formação do carvão e a obtenção de gás através da pirólise branda do material de estudo, nesse caso específico, pirólise branda de resíduos de extração de sementes de oleaginosas. Ao final do processo, observou-se que foram obtidos, os quatro produtos esperados, óleo de conversão (24.5\%), carvão (29.5\%), gás (15.25\%) e solução aquosa (32\%). O óleo de pirólise foi analisado inicialmente através de cromatografia gasosa acoplada a detector de massas. A análise do cromatograma obtido demonstrou a presença de uma classe de compostos, que possibilitaria que o mesmo fosse vir a ser utilizado como antioxidante de biocombustíveis, por apresentar derivados fenólicos, que são conhecidos como substâncias que dificultam o processo de oxidação de biodiesel. Ao se obter o óleo de pirólise caracterizado, iniciou-se uma nova etapa, processo de separação, concentração dos compostos de interesse, onde foi utilizada a técnica de cromatografia em coluna com silicagel usando três diferentes eluentes, hexano, diclorometano e metanol. Na tentativa de se obter frações com maior concentração de derivados fenólicos. Ao analisar as frações dos três eluentes utilizados, verificou-se que os compostos de interesse ficaram concentrados na fração de diclorometano, exemplificada na figura 2 e tabela 1, a seguir.

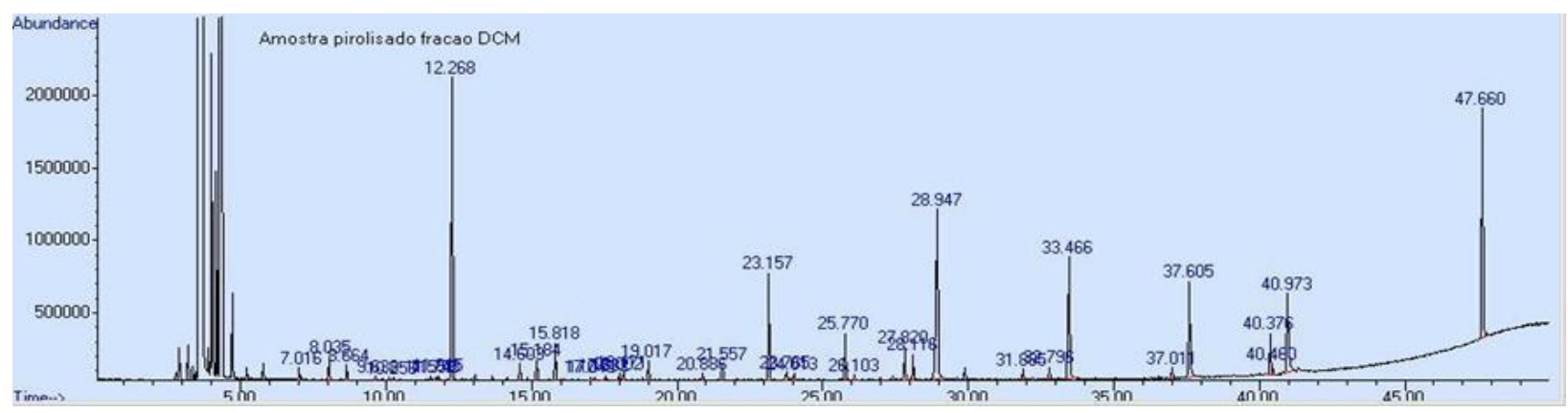

Figura 2: Perfil do cromatograma do oleo de pirólise, fração de diclorometano analisada por cromatografia gasosa com detector de massas.

$\mathrm{Na}$ Tabela 1 a seguir foram identificados diversos compostos, sendo destacados os compostos fenólicos.

Tabela 1: Substâncias fenólicas identificadas através de análise por CG-MS.

\begin{tabular}{|c|c|c|c|}
\hline \multicolumn{5}{|c|}{ Amostra pirolisado fracao DCM } \\
\hline $\begin{array}{c}\text { Tempo } \\
\text { retencão }\end{array}$ & $\begin{array}{c}\text { Área } \\
\%\end{array}$ & Composto & $\begin{array}{c}\text { Probabilidade } \\
\%\end{array}$ \\
\hline 11,812 & 0,191 & 2-Hexanol & 72 \\
\hline 12,268 & 15,624 & Fenol & 94 \\
\hline 14,604 & 0,828 & 2-Metil fenol & 95 \\
\hline 15,183 & 1,211 & 4-Metil fenol & 97 \\
\hline 15,817 & 1,919 & 2-Metoxi fenol & 95 \\
\hline 17,046 & 0,136 & Octanoato de metila & 83 \\
\hline
\end{tabular}




\begin{tabular}{|c|c|c|c|}
17,174 & 0,138 & 3-Etil fenol & 90 \\
\hline 17,53 & 0,216 & 2,4-Dimetil fenol & 91 \\
\hline 18,003 & 0,339 & 4-Etil fenol & 91 \\
\hline 18,17 & 0,562 & Acido octanoico & 91 \\
\hline 19,015 & 0,924 & 2-Metoxi-4-metil fenol & 95 \\
\hline 20,884 & 0,303 & 3-Metoxi-1,2-Benzenodiol & 91 \\
\hline 21,557 & 0,861 & 4-Etil-2-metoxi fenol & 91 \\
\hline 23,159 & 5,612 & 2,6-Diemtoxi fenol & 95 \\
\hline
\end{tabular}

O uso da fração de diclorometano do óleo de pirólise, rico em fenol, teve sua ação comprovada como antioxidante através da análise de Estabilidade Oxidativa por Rancimat. Técnica que consiste no aquecimento do biocombustível, sob fluxo constante de atmosfera oxidante, na tentativa de simular uma rápida oxidação da amostra. A amostra oxidada passa a ser rica em compostos carbonílicos, tais como cetonas. A eficácia do mesmo pode ser comprovada através dos resultados de análises de estabilidade oxidativa por Rancimat, exemplificados na tabela 2 , a seguir.

Tabela 2: Estudo da influência do bio-oleo de inajá sob a estabilidade oxidativa do biodiesel.

\begin{tabular}{cccc}
\hline $\begin{array}{c}\text { Bio óleo } \\
(\%)\end{array}$ & $\begin{array}{c}\text { Estabilidade } \\
\text { Oxidativa } \\
(\mathrm{h})\end{array}$ & Média & $\begin{array}{c}\text { Desvio } \\
\text { padrão }\end{array}$ \\
\hline 0 & 10,85 & 10,30 & 0,51 \\
0 & 10,18 & & \\
0 & 9,86 & & \\
2 & 16,60 & 18,00 & 1,36 \\
2 & 18,10 & & \\
2 & 19,31 & & \\
5 & 37,84 & 36,34 & 1,38 \\
5 & 36,06 & & \\
5 & 35,13 & & \\
20 & 44,59 & 44,58 & 0,08 \\
20 & 44,66 & & \\
20 & 44,50 & & \\
\hline
\end{tabular}

Dando continuidade aos estudos de obtenção de materiais de maior valor agregado a partir de sementes de oleaginosas, obteve-se através do processo de pirólise a baixa temperatura, aquecimento de $380^{\circ} \mathrm{C}$ e atmosfera inerte, uso de gás nitrogênio, utilizando nesse caso, uma oleaginosa diversa da anterior, a torta de extração da semente de pinhão manso, Jatropha Curcas, quatro produtos de interesse derivados deste processo. $\mathrm{O}$ carvão de pirólise foi utilizado para a obtenção de material de maior valor agregado, material adsorvente através do aquecimento do carvão em mufla, em um recipiente selado sob atmosfera inerte. Utilizando temperaturas que variaram de 500 a $1000^{\circ} \mathrm{C}$.

O carvão de pirólise foi caracterizado por diversas técnicas instrumentais e físicoquímicas, dentre essas destaca-se a análise por Infravermelho, Espectroscopia Raman, Microscopia Eletrônica, análise de pH e capacidade adsortiva. 
Tabela 3 - pH do carvão de pirólise.

\begin{tabular}{llllllll}
\hline $\begin{array}{l}\text { Carvão } \\
\text { (Celsius) }\end{array}$ & $380{ }^{\circ} \mathrm{C}$ & $500{ }^{\circ} \mathrm{C}$ & $600{ }^{\circ} \mathrm{C}$ & $700{ }^{\circ} \mathrm{C}$ & $800{ }^{\circ} \mathrm{C}$ & $900{ }^{\circ} \mathrm{C}$ & $1,000{ }^{\circ} \mathrm{C}$ \\
\hline $\mathrm{pH}$ & 9,78 & 10,53 & 10,57 & 10,59 & 10,58 & 10,56 & 10,59
\end{tabular}

Tabela 4: Resultado obtido através de Espectroscopia Raman

\begin{tabular}{lll}
\hline Sample & La & u_La \\
\hline $600^{\circ} \mathrm{C}$ & 9,06 & 0,38 \\
$800^{\circ} \mathrm{C}$ & 7,43 & 0,74 \\
$1,000^{\circ} \mathrm{C}$ & 7,77 & 0,59 \\
\hline
\end{tabular}

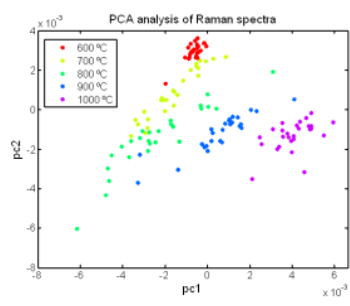

O resultado de análise por $\mathrm{pH}$ indica a obtenção de um carvão com características básicas. $\mathrm{O}$ aumento de temperatura no processo de obtenção acarreta em um pequeno aumento na basicidade do mesmo. Em relação a espectroscopia Raman, verifica-se um agrupamento no produto, através da análise de PCA. Verifica-se que os resultados de tamanho médio do cristalito (La) vão diminuindo com o aumento de temperatura, sendo esse comportamento o oposto do esperado para a obtenção de nano compostos de carbono, por exemplo.

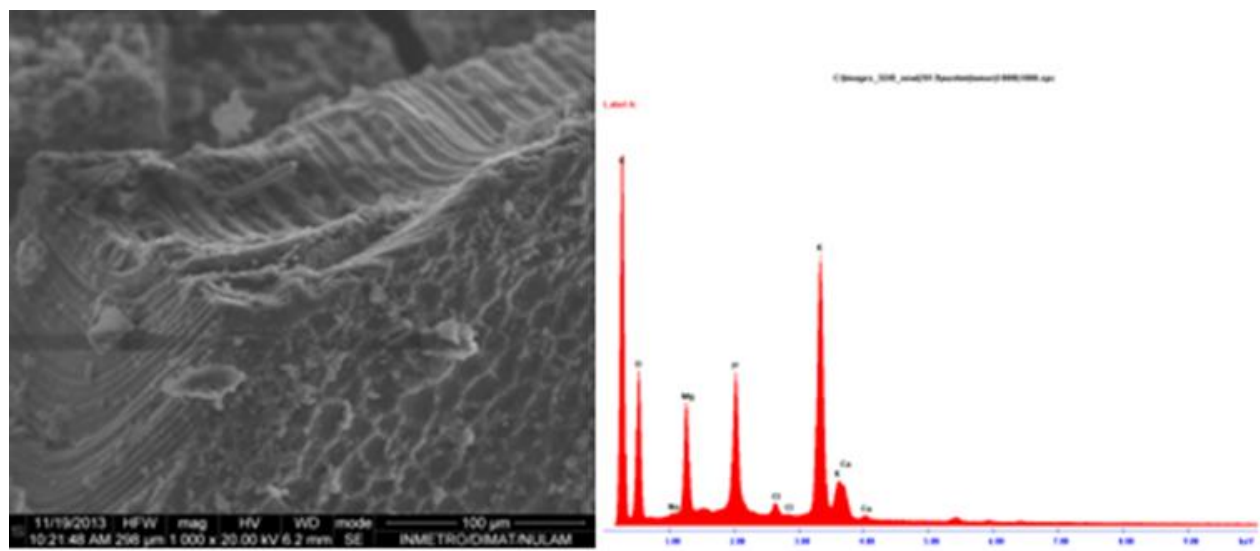

Figura 3: Resultado de análise por Microscopia eletrônica e análise por EDX.

A análise por microscopia eletrônica demonstrou a presença de contaminação do carvão por compostos alcalinos, tais como sodio e potassio, por exemplo, colaborando com os valores obtidos nas análises de teor de cinzas e de $\mathrm{pH}$, onde observou-se que o mesmo tem características básicas.

A sua capacidade adsortiva foi determinada através do uso de soluções de diversas concentrações de azul metileno, com posterior adição de carvão obtidos em variadas temperaturas 
e as mesmas eram mensuradas em aparelho de ultravioleta, observou-se a variação obtida em relação ao tempo de contato carvão - solução. Os resultados obtidos encontram-se na Figura 4.

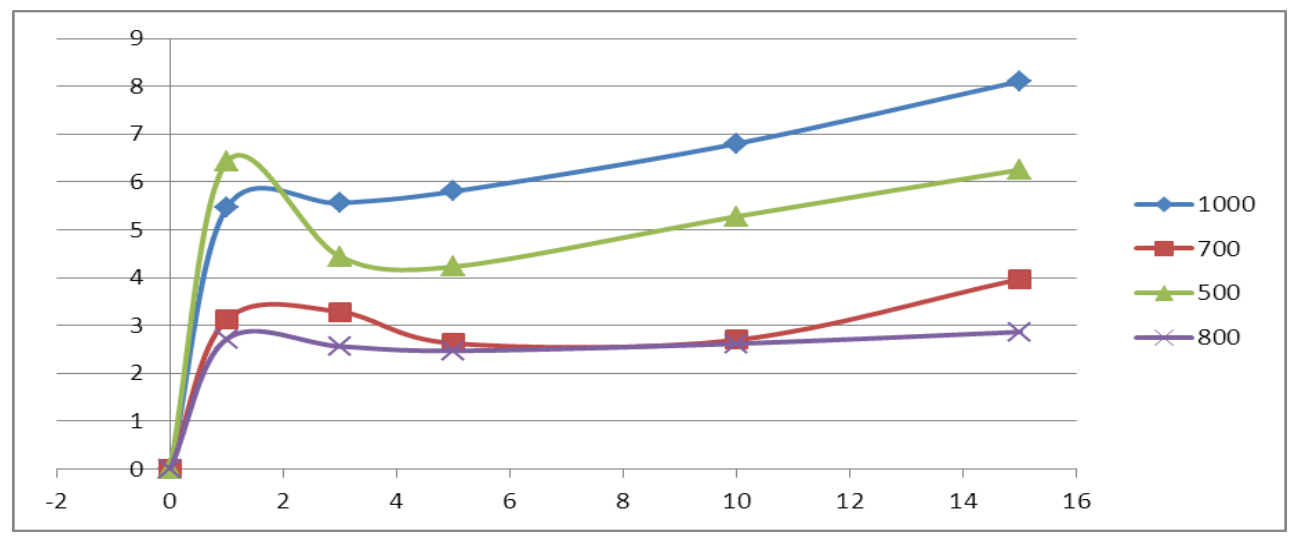

Figura 4: Gráfico obtido após análise por ultravioleta da capacidade adsortiva do carvão de pirólise (eixo x - Tempo (minutos) eixo y - Analito (mg/L)).

Ao analisar o gráfico de dispersão da Figura 4, observa-se que o carvão obtido tem a capacidade de adsorver, no caso específico, o azul de metileno em um tempo relativamente pequeno verifica-se que quanto mais tempo em contato com a solução, maior poder de adsorção. Observa-se também que a variação de temperatura para a obtenção do mesmo, não interfere na sua capacidade de adsorção.

Análise de umidade e teor de cinzas:

O resultado de teor de umidade ficou na faixa de $0.22 \%$ e o teor de cinzas na faixa de $13 \%$.

\section{CONCLUSÕES}

Observou-se que a partir do uso de rejeitos, produtos de extração de sementes de oleaginosas podem ser obtidos materiais de maior valor agregado, tais como antioxidantes e material adsorvente.

A aplicação da técnica de pirólise a baixa temperatura, $380^{\circ} \mathrm{C}$ fornece a obtenção de quatro produtos com largo campo de aplicação. O uso de rejeitos de biomassa, somado a esta técnica desenvolve-se como um novo campo para produção de materiais de larga aplicação.

A partir de semente de inajá, o óleo de pirólise após separação, filtração em coluna de silicagel obteve-se uma fração rica em fenóis. Esta teve sua ação comprovada, através da adição deste ao biodiesel, em análise de estabilidade de oxidativa por Rancimat.

O uso do rejeito de outro tipo de semente, pinhão manso, forneceu a produção de material adsorvente, que teve sua ação comprovada através de uma metodologia simples, análise por Ultravioleta. 
A comprovada eficácia da técnica e dos produtos obtidos abre o espaço para o desenvolvimento de novos produtos, através do conceito de biorefinarias. Os produtos são obtidos a partir de um processo ambientalmente favorável, onde são utilizados como matéria prima, rejeitos de biomassa, fornecendo produtos que possuem um valor comercial de grande interesse. Novos estudos estão sendo realizados para ampliar o campo de aplicação de novos materiais a vir a ser desenvolvidos.

\section{REFERÊNCIAS BIBLIOGRÁFICAS:}

${ }^{1}$ E. Bayer, U.S. 5, 114541, May 1992.

2 Figueiredo, M.K.K.; Romeiro, G. A.; Damasceno, R. N. "Low temperature conversion (LTC) of castor seeds - A study of the fraction oil (pyrolysis oil) J. Anal. Appl. Pyrolysis 2009, 86, 5357.

3 Rangabhashiyam, S.; Anu, N.; Selvaraju, N. 2013. "Sequestration of dye from textile textileindustry waste water using agricultural waste products as adsorbents". J. Envir. Chem. Engin. 2013, 1, 629-641.

4 Prussi, M.; Chiaramonti, D.; Recchia, L.; Martelli, F.; Guidotti, F.; Pari, L. "Alternative feedstock for the biodiesel and energy production: The OVEST Project". Energy 2013, 58, 2-8.

5 Deveci, H.; Kar, Y. "Adsorption of hexavalent chromium from aqueous solutions by bio-chars obtained during biomass pyrolysis" J. Ind. Eng. Chem. 2013, 19, 190-196.

6 Carrier, M.; Hardie, A. G.; Uras, U.; Gorgens, J.; Knoetze, J. H. "Production of char from vacuum pyrolysis of South-African sugar cane bagasse and its characterization as activated carbon and biochar" J. Anal. Appl. Pyrol. 2012, 96, 24-32. 